\title{
Epidemiology of New Onset Seizures and Epilepsy Cases: A Prospective Cohort Study
}

\author{
Deepak Goel ${ }^{1}$ Pradeep Aggarwal ${ }^{2} \quad$ Sunil Dutt Kandpal ${ }^{2} \quad$ Rakesh Kakkar $^{2} \quad$ Deepak Negi $^{2} \quad$ Nidhi Mittal $^{2}$ \\ ${ }^{1}$ Department of Neurology, Himalayan Institute of Medical \\ Sciences, Swami Ram Himalayan University, Doiwala, \\ Dehradun, Uttarakhand, India \\ 2Department of Community Medicine, All India Institute of Medical \\ Sciences Rishikesh, Rishikesh, Uttarakhand, India

\begin{abstract}
Address for correspondence Deepak Goel, MD, DM, Department of Neurology, Himalayan Institute of Medical Sciences, Swami Ram Himalayan University, Doiwala, Dehradun 248016, Uttarakhand, India (e-mail: goeld007in@yahoo.co.in).
\end{abstract}

Int J of Ep:2020;6:30-38

\begin{abstract}
Keywords

- unprovoked seizures

- epidemiological survey

- age-adjusted incidence
\end{abstract}

Introduction Incidence is the number of new epilepsy cases occurring during a given time interval, usually in 1 year, in a specified population. Most incidence studies of epilepsy are from developed countries with a rate of 40 to 70 per 100,000 population. Aims We conducted this survey to study incidence of all new onset unprovoked in rural and semiurban areas of the Uttarakhand State. This study is conducted on more than 100,000 of population with longitudinal follow-up of 3 years.

Methods This was a community-based, longitudinal, observational study in two blocks of Dehradun district of Uttarakhand state. Total population of approximately 100,000 from two blocks will be surveyed (50,000 in each block). This door-to-door survey was conducted annually for 3 years duration from May 2014 to April 2017. The initial data were collected on National Institute of Mental Health and Neurosciences (NIMHANS) questionnaire by door-to-door survey.

Results After longitudinal follow-up for 3 years of 103,610 of population in two blocks of Uttarakhand state, we found age-adjusted prevalence rate of unprovoked seizures to the tune of 623.63 cases per 100,000 of population. Age-adjusted incidence rate of epilepsy was 38.28 per 100,000 population and annual incidence of acute symptomatic seizures was 14.79 per 100,000 of population. Overall annual incidence rate of all afebrile seizures was 51.63 per of 100,000 people. Among all sociodemographic factors, age, poverty, diet, and hygiene were significantly associated with seizures.

Conclusion Age-adjusted incidence rate of unprovoked seizure in Uttarakhand state was 38.28 per 100,000 people. Diet and hygiene were significant risk factors for seizures.

\section{Introduction}

Prevalence studies are important to know about disease burden and incidence studies are required to know the etiology and natural course of illnesses. At the global level, it is estimated that approximately 70 million people suffer from epilepsy and prevalence of epilepsy is estimated to be 5 to 9 per 1000 population. ${ }^{1}$ Out of the 17 million disease-adjusted life years (DALYs) in global burden of epilepsy, nearly $90 \%$ are from low- and middle-income countries. Southeast Asia contributing for 3.2 million DALYs and more than half of total DALYs were accounted from India. ${ }^{1}$ Within the Southeast Asia region, the prevalence of epilepsy varied from 2 to 10 per 1,000 population. There are approximately 22 epidemiological studies on epilepsy from different parts of India, both from rural and urban areas. ${ }^{1}$ The prevalence rate stands at around 5/1,000 population (at this rate, present estimate of total population with epilepsy in this country is $\sim 6.5$ million). ${ }^{1}$

Incidence is the number of new epilepsy cases occurring during a given time interval, usually in 1 year, in a specified population. Most incidence studies of epilepsy are from developed countries with a rate of 40 to 70 per 100,000 populations. ${ }^{2}$ In 1993, Bannerjee et al, reported the incidence of 44 per 100,000 of population from Rochester 
through a 50-year follow-up period. ${ }^{2}$ Such long follow-up of population is not possible in developing countries and in India due to lack of structural health care system. There is an inherent complexity and resource intensity involved in conducting such incidence studies, thus very few incidence studies are available from India.

Studies from India have reported incidence rates varying from 27 to 60 per 100,000 population. ${ }^{1}$ Saha et al reported an incidence of 42 per 100,000 population from a 5-year longitudinal study in rural West Bengal which was similar to incidence rate of 49 per 100,000 population reported by Mani et al from the 1-year Yelandur study in rural Karnataka.,4 From urban India, rates are quite variable from 27 to 60 in two different studies. ${ }^{1}$ The main limitation to conduct an incidence study is poor health registry and case reporting at the primary health care system and nonavailability of health-related records. This type of study is more difficult in hills of Uttarakhand. Here, we conducted this survey to study incidence of all new onset unprovoked epilepsy cases in rural and semiurban areas of the Uttarakhand State. This study was conducted on large scale population of people residing in hills of Himalayas with difficult terrain and all new patients were subjected to investigation to find out possible etiology and sociodemographic linkage of all seizure cases in selected population. Also this is aimed to find out incidence of all new onset seizures cases in selected population.

\section{Methods}

\section{Study Design and Setting}

This was a community-based, longitudinal, observational study in two blocks of Dehradun district in Uttarakhand state. The Chakrata and Doiwala blocks were randomly selected by lottery. Chakrata block is least in terms of composite block index (CBI) in the district of Dehradun and covered by hills. The Chakrata block is approximately $80 \mathrm{~km}$ away from Dehradun, the capital of Uttarakhand state. This is at approximately 3,000- to 7,000-feet height from sea level with very difficult areas to reach. There are approximately 153 villages in $100 \mathrm{~km}^{2}$ area. This block is divided in nine nyay panchayat (NP). According to census 2001, total number of households and population in Chakrata block were 6,445 and 49,097, respectively. Doiwala block on the other hand is having five NP areas consists of semiurban area of plains of Uttarakhand. Out of five, only 2 NP areas (16 villages having population of about 58884 people) from Doiwala were randomly selected.

\section{Sample Size}

Total population of approximately 100,000 from two blocks had been selected for survey (50,000 in each block). Keeping the average incidence of 40 to 50 per 100,000 in India, there will be approximately 100 to 150 new cases in 3 years.

\section{Survey}

The survey team consists of field workers, supervisors, medical officer, and neurologist. The annual door-to-door survey of the whole population was conducted every year in months of April to June of 2015, 2016, and 2017. The survey was started simultaneously in both the blocks by field workers and completed in 3 months. The quality of survey was confirmed by field supervisors and medical officers. The data were collected on the prevalidated National Institute of Mental Health and Neurosciences (NIMHANS) questionnaire (used in the Yelandur study). ${ }^{4}$ Based on the Yelandur model questionnaire, one family information Performa was developed in local language (-Appendices $\mathbf{A}$ and $\mathbf{B}$ ). Each and every household were approached and head of family was interviewed for family structure, demographic details, and seizure-related information. Children below 5 years had seizure with fever (question 7) and cases having only one positive response to question 2a were excluded from analysis.

\section{Case definition:}

- Old seizure case: seizure case with onset of disease before April 30, 2014.

- New onset seizure case: case of seizure having onset after May 1, 2014.

After annual door-to-door survey, additional 3 monthly visits to the study population was done by field supervisor and medical officer of our team to check the $10 \%$ of positive and negative responders, to complete the information of missing data, to collect the information of locked houses, and to find any new onset seizure case in community. Those household having new onset seizure case(s) were approached by our field supervisor and medical officer to record detail information about age of onset of seizure, type of seizure, frequency of seizure episodes, family history of seizure, reports of investigations done for seizures, and treatment taken with response to treatment. If no investigation done in new onset cases, then they were subjected to magnetic resonance imaging (MRI) and electroencephalography (EEG). Analysis of data was done at the end of 3 years. New onset seizure cases having obvious provoking factors like seizures during hospitalization due to any illness other than seizure disorder, seizure with febrile illness, headache, and vomiting, seizure within 7 days due to acute central nervous system (CNS) insult-like head injury, and seizures in a person with substance abuse were excluded from analysis. Cases with single-seizure episode were included but patients with new onset status epilepticus were not included.

Classification of seizures and etiology was based on International League Against Epilepsy (ILAE) classification system for epidemiological studies in $1993 .{ }^{6}$ Based on the 1993 ILAE classification, seizures were of three types (generalized, partial, and unclassified) and etiologies were classified (on the basis of clinical, EEG, and radiological findings) into acute symptomatic, remote symptomatic, idiopathic, and unknown. Other operational definitions were same as defined according to ILAE commission report $1997 .{ }^{7}$

\section{Operational Definitions}

Epilepsy: two or more unprovoked seizures or seizure episode. An unprovoked seizure is one without an acute underlying cause. 
Single-seizure episode: isolated or multiple seizures episode within 24 hours.

Status epilepticus: single or multiple seizures without regaining consciousness for more than 30 minutes.

Active epilepsy: a person with seizure in past 5 years regardless of treatment status.

Febrile seizure: seizure in a child between 6 months and 5 years of age with fever (not due CNS infection).

\section{Definition of Putative Etiology}

Symptomatic seizures: symptomatic seizures or epilepsies are considered the consequence of a known or suspected cerebral disease. Acute symptomatic seizures defined as seizure occurring in close temporal association with an acute systemic, metabolic, or toxic insult or in association with an acute CNS insult. Such seizures are often isolated epileptic events associated with acute conditions, but may also be recurrent seizures or even status epilepticus when the acute conditions recurs.

Unprovoked seizures: seizures may occur in relation to well demonstrated antecedent conditions, substantially increasing the risk for epileptic seizures.

Unprovoked seizures of unknown etiology: cases of unprovoked seizures for which no clear antecedent etiology can be detected.

Idiopathic epilepsies: used herein as defined by the ILAE and must be reserved for certain partial or generalized epileptic syndromes with particular clinical characteristics and with specific EEG findings and should not be used to refer to epilepsy or seizures without obvious cause.

Cryptogenic epilepsies: used to include partial or generalized unprovoked seizures in which no factor associated with increased risk of seizures has been identified.

Non epileptic event: clinical manifestations presumed to be unrelated to an abnormal and excessive discharge of a set of neurons of the brain, including disturbances in brain function and pseudo seizures.

\section{Seizure Type Classification}

Generalized seizures: a seizure is considered generalized when clinical symptomatology provides no indication of an anatomic localization and no clinical evidence of focal onset.

Partial seizure: a seizure should be classified as partial onset when there is evidence of a clinical partial onset, regardless of whether the seizure is secondarily generalized.

Multiple seizure: when both generalized and partial seizures occur.

Unclassified seizure: used when it is impossible to classify seizures, owing to lack of adequate information.

\section{Measurable Epidemiological Index}

Period prevalence: the proportion of patients with epilepsy in a given population during a defined time interval.

Incidence rate: the ratio of new cases to population at risk, usually expressed as cases per 100,000 of population per year.

\section{Quality Control}

Field workers and supervisors were trained at the Department of Community Medicine, Himalayan Institute of Medical Sciences in Dehradun for questionnaire filling, seizure-related history, true seizures, and nonepileptic seizures for the field work, and to know about provoked seizures like febrile convulsions and alcohol-related seizures or other metabolic toxic conditions. Hot water epilepsy and other reflex epilepsy are not found in this area. These workers were also the part of our team while we performed prevalence study in year 2008 with the same questionnaire, therefore validation and sensitivity/specificity assessment was not conducted. ${ }^{8}$

\section{Statistical Analysis for Epidemiological Parameters Measured in Current Study}

Prevalence: included all surviving cases of seizures before May 1, 2014. Prevalence was expressed as numbers per 100,000 of population.

Annual incidence rate (AIR): indicates new cases of epilepsy per 100,000 of population per year. The average AIR (AAIR) indicates average of all 3 years for new cases per 100,000 of population per year.

Age standardization: The age standardization of prevalence and incidence rates was done with World Standard Population (WSP) according to Ahmad et al. ${ }^{9}$ The $95 \%$ confidence interval $(\mathrm{CI})$ of incidence and prevalence were calculated assuming a Poisson's distribution of the observed cases.

SPSS 20 version was used for frequency analysis and regression analysis (univariate and multivariate analyses). All seizure cases cluster was analyzed for various sociodemographic parameters and labeled as significant if $p<0.05$.

\section{Result}

A total of 7,649 households (56,399 population) in nine NP areas of Chakrata block and 10,874 households (47,211 population) in Doiwala block were surveyed. Among total population of 103,610 (54,158 men and 49,452 women), living in 26,172 households were screened. Distribution of age, gender, and sociodemographic variables in the selected population is given in $\boldsymbol{- T a b l e} \mathbf{1}$. The $\boldsymbol{-}$ Table $\mathbf{1}$ also shows significance of various sociodemographic parameters in relation with seizure cluster. Age, gender, caste, and poverty level were significant factors linked with seizure cluster on univariate analysis. Among dietary and personal hygiene-related factors, nonvegetarian diet, mud house, nonavailability of separate kitchen and/or toilet, and source of drinking water were found significantly associated with seizure patients. Education, occupation, and overcrowding were not found significant in association with seizures cases on univariate analysis. On multivariate analysis (-Table 2 ) on all seizures patients, age, nonvegetarian diet, and separate kitchen were significantly associated with seizure patients.

After first survey, a total of 783 had positive response for seizure with 733 old cases and 50 new onset cases among 103,610 people. Additional four old cases were found in $10 \%$ of negative responders, so 40 cases added to a total of 773 cases (746.06 per 100,000). A total of 83 children below 5 years had febrile 
Table 1 Profile of whole population according to sociodemographic parameters

\begin{tabular}{|c|c|c|}
\hline Variable & $\begin{array}{l}\text { Frequency } \\
n(\%)\end{array}$ & $\begin{array}{l}\text { Association of demographic variable } \\
\text { with seizure on univariate analysis } \\
\text { ( } p \text {-value) }\end{array}$ \\
\hline Total population surveyed & $103,610(100)$ & \\
\hline $\begin{array}{l}\text { Total seizure cases over } 3 \text { years } \\
\text { No seizure population }\end{array}$ & $\begin{array}{l}833(0.8) \\
102,777(99.2)\end{array}$ & \\
\hline $\begin{array}{l}\text { Gender } \\
\text { 1. Male } \\
\text { 2. Female }\end{array}$ & $\begin{array}{l}54,158(52.3) \\
49,452(47.7)\end{array}$ & 0.005(significant) \\
\hline $\begin{array}{l}\text { Age group (y) } \\
\text { 1. Early childhood (0-4) } \\
\text { 2. Late childhood (5-14) } \\
\text { 3. Adolescent (15-19) } \\
\text { 4. Adults (20-59) } \\
\text { 5. Elderly }(>60)\end{array}$ & $\begin{array}{l}8,141(7.9) \\
22,325(21.5) \\
10,775(10.4) \\
53,785(51.9) \\
8,584(8.3)\end{array}$ & 0.000 (significant) \\
\hline $\begin{array}{l}\text { Caste } \\
\text { 1. General } \\
\text { 2. OBC } \\
\text { 3. Schedule cast } \\
\text { 4. Schedule tribe }\end{array}$ & $\begin{array}{l}45,430(43.8) \\
2,555(2.5) \\
19,475(18.8) \\
36,150(34.9)\end{array}$ & 0.001 (significant) \\
\hline $\begin{array}{l}\text { Poverty level } \\
\text { 1. APL } \\
\text { 2. BPL }\end{array}$ & $\begin{array}{l}73,970(71.4) \\
29,640(28.6)\end{array}$ & 0.000 (significant) \\
\hline $\begin{array}{l}\text { Education } \\
\text { 1. Post graduate } \\
\text { 2. Graduate } \\
\text { 3. Intermediate } \\
\text { 4. High school } \\
\text { 5. Primary } \\
\text { 6. Illiterate }\end{array}$ & $\begin{array}{l}1,728(1.7) \\
5,465(5.3) \\
12,931(12.5) \\
7,981(7.7) \\
46,997(45.4) \\
28,508(27.5)\end{array}$ & 0.075 (not significant) \\
\hline $\begin{array}{l}\text { Occupation of family head } \\
\text { 1. Business (own work) } \\
\text { 2. Farming } \\
\text { 3. Service (with retired) } \\
\text { 4. Labor class (daily wedges) }\end{array}$ & $\begin{array}{l}12,807(12.4) \\
72,858(70.3) \\
11,878(11.5) \\
6,067(5.9)\end{array}$ & 0.808 (not significant) \\
\hline $\begin{array}{l}\text { Major diet pattern } \\
\text { 1. Vegetarian } \\
\text { 2. Nonvegetarian }\end{array}$ & $\begin{array}{l}30,029(29) \\
73,581(71)\end{array}$ & 0.000 (significant) \\
\hline $\begin{array}{l}\text { House type } \\
\text { 1. Kuccha (mud house) } \\
\text { 2. Pukka (bricked) } \\
\text { 3. Mixed }\end{array}$ & $\begin{array}{l}6,934(6.7) \\
90,914(87.7) \\
5,762(5.6)\end{array}$ & 0.036 (significant) \\
\hline $\begin{array}{l}\text { Separate kitchen } \\
\text { 1. No } \\
\text { 2. Yes }\end{array}$ & $\begin{array}{l}8,504(8.2) \\
95,106(91.8)\end{array}$ & 0.000 (significant) \\
\hline $\begin{array}{l}\text { Separate toilet } \\
\text { 1. No } \\
\text { 2. Yes }\end{array}$ & $\begin{array}{l}16,801(16.2) \\
86,809(83.8)\end{array}$ & 0.000 (significant) \\
\hline $\begin{array}{l}\text { Source of water } \\
\text { 1. Community water source/hand pump } \\
\text { 2. Owned tap }\end{array}$ & $\begin{array}{l}15,631(15.1) \\
87,979(84.9)\end{array}$ & 0.000 (significant) \\
\hline
\end{tabular}

Abbreviations: APL, above poverty line; BPL, below poverty line; OBC, other backward class.

convulsion and they were excluded from analysis. Additional 22 cases excluded, as they responded for only one episode of unconsciousness and all other responses were negative (possible nonepileptic event). Thus, a total of 668 old cases of all afebrile seizures (active cases) were finally analyzed for the crude prevalence rate (with 95\% CI) of 648.67 (537.26-760.08) per 100,000 of population. The crude prevalence among men was 757.93 (95\% CI: 639.95-875.91) and in women was 577.85 (95\% Cl: 391.28-764.42). When age standardization to WSP done, overall prevalence was 623.63 (95\% CI: 510.03-737.23) per 100,000 population; mean age-adjusted prevalence rate (AAPR) was 762.03 (95\% CI: 642.53-881.53) and among women was 472.01 (95\% CI: 323.71-620.31) per 100,000 population ( - Table 3). Linear graph in - Fig. 1 showed that AAPR is having 
34 New Onset Seizures and Epilepsy Cases Goel et al.

Table 2 Multivariate analysis of all seizure patients with sociodemographic factors

\begin{tabular}{|l|l|l|l|l|}
\hline Parameter & Significance & \multirow{2}{*}{ Odd ratio } & \multicolumn{2}{|c|}{$95 \% \mathrm{Cl}$} \\
\cline { 4 - 5 } & & & & Upwer \\
\hline Age group & 0.000 & & & \\
\hline Late childhood & 0.000 & 0.475 & 0.313 & 0.722 \\
\hline Adolescent & 0.000 & 0.262 & 0.172 & 0.401 \\
\hline Adult & 0.000 & 0.334 & 0.225 & 0.497 \\
\hline elderly & 0.000 & 0.424 & 0.268 & 0.672 \\
\hline Caste & 0.518 & & & \\
\hline OBC & 0.715 & 1.121 & 0.931 & 1.349 \\
\hline SC & 0.993 & 1.033 & 0.672 & 1.586 \\
\hline ST & 0.227 & 1.122 & 0.925 & 1.362 \\
\hline APL/BPL & 0.024 & 1.208 & 1.025 & 1.424 \\
\hline Vegetarian/nonvegetarian & 0.001 & 1.392 & 1.155 & 1.678 \\
\hline Type of house & 0.209 & & & \\
\hline Mud house & 0.154 & 1.24 & 0.922 & 1.666 \\
\hline Mixed house & 0.183 & 1.237 & 0.904 & 1.693 \\
\hline Separate kitchen & 0.012 & 1.37 & 1.071 & 1.753 \\
\hline Separate toilet facility & 0.75 & 1.046 & 0.794 & 1.378 \\
\hline Main source of drinking water & 0.469 & 1.103 & 0.846 & 1.437 \\
\hline A & & & \\
\hline
\end{tabular}

Abbreviations: APL, above poverty line; BPL, below poverty line; CI, confidence interval; OBC, other backward class; SC, schedule cast; ST, schedule tribe.

Table 3 Age- and gender-specific rates of all seizure cases

\begin{tabular}{|c|c|c|c|c|c|c|c|c|c|}
\hline & \multicolumn{3}{|c|}{ Men } & \multicolumn{3}{|c|}{ Women } & \multicolumn{3}{|c|}{ Overall } \\
\hline Age (y) & POP & PR & AAIR & POP & PR & AAIR & POP & PR & AAIR \\
\hline $0-4$ & 4,288 & 233.2 & 62.2 & 3,853 & 181.68 & 25.95 & 8,141 & 208.82 & 45.04 \\
\hline $5-9$ & 5,655 & 477.45 & 47.1 & 4,978 & 361.59 & 13.4 & 10,633 & 423.21 & 31.34 \\
\hline $10-14$ & 6,100 & 688.52 & 76.5 & 5,592 & 608.01 & 59.6 & 11,692 & 650.01 & 68.42 \\
\hline 15-19 & 5,696 & 842.7 & 46.8 & 5,079 & $1,102.58$ & 72.2 & 10,775 & 965.2 & 58.77 \\
\hline $20-24$ & 4,710 & 976.65 & 77.8 & 4,412 & $1,087.94$ & 52.9 & 9,122 & $1,030.48$ & 65.77 \\
\hline $25-29$ & 4,619 & 844.34 & 57.7 & 4,613 & 845.44 & 43.4 & 9,232 & 844.89 & 50.54 \\
\hline $30-34$ & 4,230 & 898.35 & 55.2 & 3,826 & 731.83 & 43.56 & 8,056 & 819.27 & 49.65 \\
\hline $35-39$ & 3,915 & 817.37 & 42.6 & 3,974 & 427.78 & 50.3 & 7,889 & 621.12 & 46.47 \\
\hline $40-44$ & 3,536 & 791.86 & 94.3 & 2,864 & 558.66 & 34.9 & 6,400 & 687.5 & 67.7 \\
\hline $45-49$ & 2,826 & $1,026.19$ & 47.2 & 2,461 & 365.7 & 40.6 & 5,287 & 718.74 & 44.1 \\
\hline $50-54$ & 2,120 & 801.9 & 31.4 & 1,960 & 663.27 & 51.02 & 4,080 & 735.29 & 40.85 \\
\hline 55-59 & 1,870 & 748.66 & 53.5 & 1,849 & 432.67 & 54.08 & 3,719 & 591.56 & 53.78 \\
\hline $60-64$ & 1,562 & 704.23 & 106.7 & 1,617 & 494.74 & 41.22 & 3,179 & 597.67 & 73.4 \\
\hline 65-69 & 1,341 & $1,267.71$ & 24.86 & 1,143 & 349.96 & 58.3 & 2,484 & 845.41 & 40.26 \\
\hline $70-74$ & 863 & 811.12 & 38.6 & 640 & 625 & 104.1 & 1,503 & 731.87 & 66.53 \\
\hline $75-79$ & 425 & 705.88 & 78.4 & 305 & 0 & 0 & 730 & 410.96 & 45.66 \\
\hline $80+$ & 402 & 248.76 & 82.9 & 286 & 0 & 0 & 688 & 145.35 & 48.45 \\
\hline TOTAL & 54,158 & 757.93 & 60.2 & 49,452 & 519.81 & 43.85 & 103,610 & 648.67 & 52.74 \\
\hline $95 \% \mathrm{Cl}$ & & $\begin{array}{l}\text { 639.95- } \\
875.91\end{array}$ & $\begin{array}{l}49.78- \\
70.66\end{array}$ & & $\begin{array}{l}373.82- \\
665.8\end{array}$ & $\begin{array}{l}32.12- \\
55.58\end{array}$ & & $\begin{array}{l}537.26- \\
760.08\end{array}$ & $\begin{array}{l}47.21- \\
58.27\end{array}$ \\
\hline ASR & & 762.03 & 59.2 & & 472.01 & 43.53 & & 623.63 & 51.63 \\
\hline $95 \% \mathrm{Cl}$ & & $\begin{array}{l}642.53- \\
881.53\end{array}$ & $\begin{array}{l}48.78- \\
69.64\end{array}$ & & $\begin{array}{l}323.71- \\
620.31\end{array}$ & $\begin{array}{l}32.11- \\
54.95\end{array}$ & & $\begin{array}{l}510.03- \\
737.23\end{array}$ & $\begin{array}{l}46.69- \\
56.57\end{array}$ \\
\hline
\end{tabular}

Abbreviations: ASR, age standardize rate; AAIR, age-adjusted incidence rate; $\mathrm{CI}$, confidence interval; POP, population; PR, prevalence rate. 
bimodal pattern with initial peak at 20 to 25 years and second peak around 70 years.

After 3 years, a total of 201 cases of new onset seizures were recorded in selected community (-Table 4). Total 36 cases having obvious provocation factor (febrile illness in 22 , substance abuse in 6 , acute head injury in 5 , and, during hospital stay, 3 patients for other illness) were excluded. Therefore total 165 cases (mean $=55$ cases per year) were found without any obvious provoking factors. - Table 5 shows the etiological distribution of all new onset seizures cases without provoking factor in both the blocks under surveillance. Overall crude incidence rate for all new onset seizures cases was 52.74 (95\% CI: 47.21-58.27) per 100,000 population. Among men, crude incidence rate was 60.2 (95\% CI: 49.78-70.66) and in women, it was 43.85 (95\% CI: $32.12-55.58$ ) per 100,000 population. Overall age-adjusted IR (AAIR) for all new onset seizures

PR

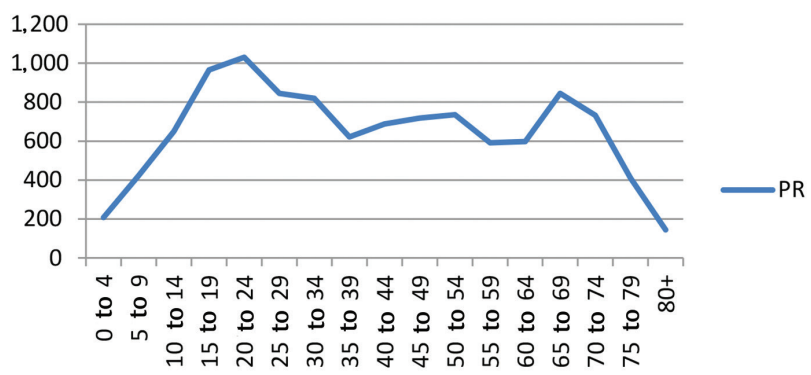

Fig. 1 Age-specific pattern of prevalence of epilepsy. PR, prevalence rate. was 51.63 (95\% CI: 46.69-56.57), among men it was 59.2 (95\% CI: 48.70-69.64), and among women AAIR was 43.53 (95\% CI: $32.11-54.95$ ) per 100,000 population (-Table 3 ). -Fig. 2 shows bimodal peak of annual incidence rate at 20 to 39 years and more than 60 years age group.

After investigations done in all new onset seizure cases, 46 cases (27.9\%) were having brain granuloma/acute illness as a cause of seizure. Annual incidence rate of acute symptomatic seizures (with intracranial granuloma/acute illness) was, 14.79 per 100,000 of people. Therefore, the annual incidence rate of all unprovoked seizures or epilepsy (after excluding acute symptomatic seizures) was 38.28 cases per 100,000 of population (included remote symptomatic, primary generalized and unclassified epilepsy). - Table 5 also showed the seizure type among all new onset cases and suggested nearly equal distribution of generalized, partial, and unclassified seizures.

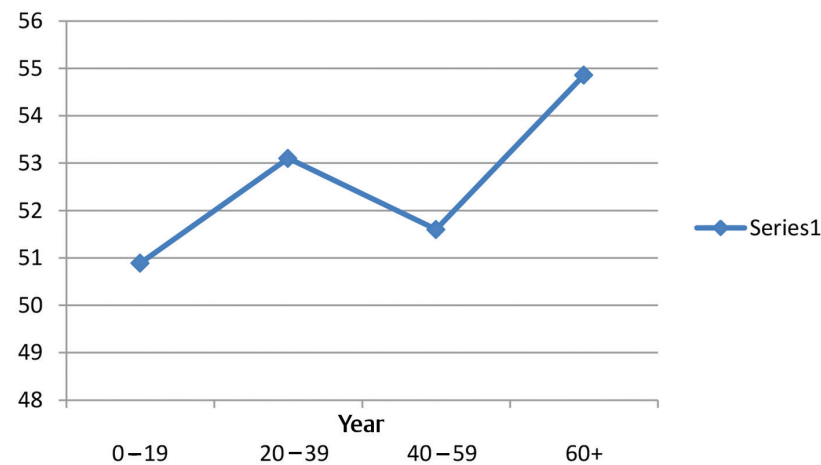

Fig. 2 Pattern of age-specific annual incidence rate (per 100,000) population.

Table 4 The number of population and household selected for survey

\begin{tabular}{|l|l|l|l|l|l|l|l|}
\hline Block & $\begin{array}{l}\text { Panchayat } \\
\text { area }\end{array}$ & $\begin{array}{l}\text { House } \\
\text { hold }\end{array}$ & Population & $\begin{array}{l}\text { All seizure } \\
\text { cases } \\
\text { Onset before } \\
\text { 2014 }\end{array}$ & $\begin{array}{l}\text { New onset } \\
\text { seizure } \\
\text { cases } \\
(\mathbf{2 0 1 4 - 1 5 )}\end{array}$ & $\begin{array}{l}\text { New onset } \\
\text { seizure cases } \\
\text { (2015-16) }\end{array}$ & $\begin{array}{l}\text { New onset seizure } \\
\text { cases (2016-17) }\end{array}$ \\
\hline $\begin{array}{l}\text { Chakrata } \\
\text { block }\end{array}$ & 9 areas & 7,649 & $\begin{array}{l}56,399 \\
\text { Male }=28,959 \\
\text { Female }=27,440\end{array}$ & 422 & 26 & 28 & 32 \\
\hline $\begin{array}{l}\text { Doiwala } \\
\text { block }\end{array}$ & 8 areas & 10,874 & $\begin{array}{l}47,211 \\
\text { Male }=25,199 \\
\text { Female }=22,012\end{array}$ & 246 & 24 & 25 & 30 \\
\hline $\begin{array}{l}\text { Grand } \\
\text { total }\end{array}$ & 17 areas & 18,523 & $\begin{array}{l}103,610 \\
\text { Male }=54,158 \\
\text { Female }=49,452\end{array}$ & 668 & 50 & 53 & 62 \\
\hline
\end{tabular}

Table 5 Etiology and type of seizure among new onset cases

\begin{tabular}{|l|l|l|l|}
\hline Etiology & Doiwala block $(\boldsymbol{n}=\mathbf{8 6})$ & Chakrata block $(\boldsymbol{n}=\mathbf{7 9})$ & $\begin{array}{l}\text { Average annual Incidence rates according } \\
\text { to etiology per 100,000 population }\end{array}$ \\
\hline $\begin{array}{l}\text { Acute symptomatic } \\
\text { (granuloma) }\end{array}$ & $21(27.8 \%)$ & $25(28.8 \%)$ & 14.79 \\
Remote symptomatic & $10(12.7 \%)$ & $11(12.8 \%)$ & .76 \\
Primary/idiopathic & $4(5 \%)$ & $6(7 \%)$ & 3.21 \\
Unknown etiology & $44(54.5 \%)$ & $44(51.2 \%)$ & 28.31 \\
\hline Type of seizure: & & & \\
Generalized & 38 & 21 & $59(35.8 \%)$ \\
Focal & 24 & 24 & $48(29 \%)$ \\
Unclassified & 24 & 34 & $58(35.2 \%)$ \\
\hline
\end{tabular}




\section{Discussion}

After the 2010 study that was conducted in East India, ${ }^{10}$ this is another longitudinal follow-up study over 3 years conducted in the Northern part of India. This study was done with standard way of definitions, age standardization according to WSP, and door-to-door survey. Over 100,000 of population were followed to find new onset seizures in the community and their etiological profile. This study was in continuation of our pilot study done in same geographical area on 14,000 of population to find out crude prevalence rate. ${ }^{8}$ In our study, we did not record data on mortality of patients suffering from seizures, so could not analyze standard mortality rates (SMRs) among persons with epilepsy.

According to a review done by Banerjee et al, ${ }^{2}$ a total of 48 prevalence studies for epilepsy cases were conducted globally among which 29 studies had used door-to-door method of community-based survey. AAPR of epilepsy were 500 to 710 per 100,000 people in North America, 370 to 2,200 per 100,000 in Central and South America, 270 to 700 per 100,000 in Europe, and highest was in Nigeria with 4,400 cases per 100,000 population. ${ }^{2}$ In another review by Amudhan et al in 2015, total 23 studies from rural and 22 from urban India were mentioned that have analyzed the prevalence rates in different Indian areas. ${ }^{1}$ Both crude and age-adjusted prevalence of epilepsy in all ages were ranging from lowest prevalence rate of 130 cases per 100,000 from Baroda and Pondicherry and highest prevalence rate of 1,004 cases per 100,000 population from West Bengal and Karnataka. ${ }^{1}$ AAPR was 572.80 per 100,000 in a study by Banerjee et al in 2010 which was similar to Sridharan et al in $1999 . .^{10,11}$ In our study, we found little higher AAPR of active unprovoked seizures 623.63 per 100,000 population. The higher prevalence of epilepsy is due to higher rates on neurocysticercosis leading to permanent epileptogenic focus as mentioned in earlier studies. ${ }^{12}$ Most of the studies form developing countries showed a stable pattern of AAPR rate of epilepsy up to forth decade then fall of the rates fifth decade onward, but our study showed bimodal pattern with first peak in second to third decade and other peak at 6th - 7th decade. ${ }^{10}$ Most of the studies on age-specific prevalence showed peak during early childhood or adolescence, ${ }^{2}$ our study also showed peak at adolescent age group ( $1.2 \%$ in adolescents vs. $0.8 \%$ overall). Gender-specific prevalence in most studies and our study showed higher prevalence in males (7.57 vs. 5.19 ).

Regarding AAIR of epilepsy, a total of 15 studies were recorded with definition of recurrent unprovoked seizures. ${ }^{2}$ In North America, AAIR ranged from 16 to 51 per 100,000, 111 per 100,000 in South America, 26 to 47 per 100,000 from Europe, and 43 to 51 per 100,000 from African region. ${ }^{2}$ Four Indian studies have analyzed the incidence rates of epilepsy till 2015 review. ${ }^{1}$ Two studies with 5-year longitudinal follow-up of selected population to study AAIR, found incidence rate of 42 per 100,000 (20,966 population) from West Bengal in 2008 and 27 per 100,000 (52,377 population) again from West Bengal in 2010, ${ }^{3,9}$ One study by Amudhan et al from Chandigarh found AAIR of 60 per 100,000 of population in 4-year follow-up. ${ }^{1}$ The first incidence study in India was conducted by Mani, et al from Karnataka, and found AAIR of 49.3 per 100,000 of population in 1-year follow-up. ${ }^{5}$ Overall, AAIR of all new onset seizure cases (after excluding seizures with obvious provoking factors) in our study was 51.63 per 100,000 of population. We were following all new onset seizures cases in community area at every three months interval with clinical survey and investigations available, and found AAIR of 14.79 per 100,000 for acute symptomatic seizures either due to cerebral cysticercosis/tuberculoma (granuloma related). Finally, AAIR of epilepsy (unprovoked seizures) in our study was 38.28 cases per 100,000 of population after exclusion of acute symptomatic seizures.

Methodological issues in door-to-door survey of epilepsy are case ascertainment, determination of etiology, not missing the actual cases, and overdiagnosis of nonepileptic cases. ${ }^{2}$ In current study, case ascertainment and case definition was not only dependent on door-to-door survey but information was gathered by multiple sources as suggested earlier. ${ }^{2}$ We took information from Accredited social health activists (ASHA) workers, head of panchayat area, head of family, and medical record checkup. Along with this, we had established community-based epilepsy clinic there for treatment of epilepsy, so there was good clinical evaluation done for confirmation of case and etiology. Second methodological challenge we faced that it was easy to recognize various provoking factors of seizures like febrile seizure, alcohol-related seizure, and acute CNS injury-related seizures, but case of acute symptomatic seizures due to granuloma were difficult to recognize on clinical interview alone. For diagnosis of acute symptomatic seizures due to granuloma, we needed imaging, so that these cases always get registration in door-to-door survey.$^{10}$ The wide variation of prevalence and incidence rates of epilepsy in different national and international studies depends on the methods used, as well as on the population selected as study from endemic area for neurocysticercosis would show high rates. ${ }^{11}$

After statistical analysis diet pattern and hygiene-related social factors were found significant as nonvegetarian diet, nonavailability of separate toilet/kitchen and community source of water were having high prevalence of seizures. Since the selected population is in high-endemic zone for neurocysticercosis, many of these patients can become chronic epilepsy patient in long-term follow-up. ${ }^{11}$ Open field defecation and poor water sanitation can increase prevalence of neurocysticercosis and overall chronic epilepsy due to calcified granuloma. ${ }^{12}$ We propose that improvement with close toilet facility and better water sanitation can reduce overall disease burden in long-term follow-up.

\section{Strength and Limitation}

Strength of the current study is the large population with evaluation of all new onset seizure cases by neurologist to recognize the correct and etiological evaluation of all new cases. Limitation was that we have only 3 years to follow-up and longer duration would have been better. Other weak 
points of current study were not accounting for single seizure, not included data on death of seizure patients, and no account for refractory epilepsy.

\section{Conclusion}

After longitudinal follow-up for 3 years among 103,610 population in two blocks of Uttarakhand state, we found AAPR of all seizures cases to the tune of 623.63 cases per 100,000 of population. Overall annual incidence rate of all seizure cases was 51.63 per 100,000 population. AAIR rate of epilepsy was 38.28 per 100,000 population and annual incidence of acute symptomatic seizures was 14.79 per 100,000 of population.

Diet patterns and hygiene-related factors were significantly associated with seizure cases in selected community. We propose that open field defecation can be high risk for increasing epilepsy burden in our community and close toilets with water sanitation will be helpful to reduce disease burden.

\section{Conflict of Interest}

None declared.

\section{Acknowledgment}

This study was funded by Indian Council of Medical Research (ICMR) for conducting 3 years of community survey.

\section{References}

1 Senthil A, Gururaj G, Satishchandra P. Epilepsy in India I: Epidemiology and Public health. Ann Indian Acad Neurol 2015; 18: 263-277

2 Banerjee PN, Fillipi D, Houser WA. The Descriptive Epidemiology of Epilepsy - A Review. Epilepsy Res. 2009; 85: 31-45

3 Hauser WA, Annegers JF, Kurland LT. Incidence of Epilepsy and unprovoked seizures in Rochester Minnesota: 1935-1984. Epilepsia 1993; 34: 543-68
4 Saha S.P, Bhattachrya S, Roy B.K, Basu A, Roy T, Maity B, Das S.K. A prospective incidence study of epilepsy in a rural community of West-Bengal, India. Neurology Asia 2008; 13:41-48

5 Mani KS, Rangan G, Srinivas HV, Kalyanasundaram S, Narendran S, Reddy AK. The Yelandur study: a community-based approach to epilepsy in rural south India-epidemiological aspects. Seizure 1998; 7: 281-8

6 Guidelines for Epidemiologic Studies on Epilepsy: Commission on Epidemiology and Prognosis, International League Against Epilepsy. Epilepsia 1993; 34: 592-96

7 ILAE Commission Report. The Epidemiology of Epilepsies: Future Directions. Epilepsia 1997; 38: 614-18

8 Goel D, Agarwal A, Dhanai JS, Semval VD, Mehrotra V, Saxena V, Maithili B. Comprehensive Rural Epilepsy surveillance programme in Uttarakhand state of India. Neurol India. 2009;57:355-6

9 Ahmed OB, Boschi- Pinto C, Lopez AD, Murray CJL, Lozano R, Inoue M. Age Standardization of rates: A New WHO Standard (GPE Discussion Paper Series No. 31); 2000: World Health Organization, Geneva

10 Banerjee TK, Ray BK, Das SK, Hazra A, Ghosal MK, Chaudhuri A et al. A Longitudinal Study of Epilepsy in Kolkata, India. Epilepsia 2010; 51: 2384-91

11 Sridharan R, Murthy BN. Prevalence and Pattern of epilepsy in India. Epilepsia 1999; 40: 631-36

12 Goel D, Agarwal A, Dhanai JS, Mehrotra V, Saxena V. Neurocysticercosisand its impact on crude prevalence rate of epilepsy in an Indian community. Neurology India 2011; 59 : 37-40

13 Sawhney IM, Singh A, Kaur P, Suri G, Chopra JS. A case control study and one year follow up of registered epilepsy cases in a resettlement colony of North India, a developing tropical country. J Neurol Sci 1999; 165: 31-5

14 Moyano LM, Saito M, Montano SM, Gonzalvez G, Olaya S, et al. Neurocysticercosis as a cause of epilepsy and seizure in two community-based studies in a cysticercosis endemic region in Peru. PLoS Negl Trop Dis 2014; 8: e2692. Doi:10.1371/journal. pntd.0002692

15 Coral-Almeida M, Gabriel S, Abath EN, Preat N, Benitez W, Dorny P. Taenia solium human cysticercosis: A systemic review of sero-epidemiological data from endemic zones around the World. PLos Negl Trop Dis 2015; 9: e0003919. Doi: 10. 1371/ journal.pntd.0003919 